The Research Journal of the Costume Culture

[Original Article]

Received June 19, 2017

Revised August 10, 2017

Accepted August 16, 2017

${ }^{\dagger}$ Corresponding author

(gimill@kookmin.ac.kr)

ORCID

Jungwoo Kim

http://orcid.org/0000-0003-1449-1157

III Kim

http://orcid.org/0000-0003-0826-1355

\section{Effect of sports taping on golf swing when wearing functional inner-wear}

\author{
Jung-Woo Kim and Ill-Kim ${ }^{* \dagger}$ \\ Dept. of Stylist, Yongin Songdam College, Korea \\ Dept. of Fashion Design, Kookmin University, Korea*
}

\section{기능성 이너웨어 착용 시 스포츠 테이핑 부착에 따른 골프 스윙에 미치는 효과}

\author{
김 정 우 · 김 일 $^{*+}$ \\ 용인송담대학 스타일리스트과, 국민대학교 의상디자인학과*
}

\begin{abstract}
Functional inner-wear being currently sold is being made without regard to the characteristics of various sports events. The purpose of this study is to identify this problem and to investigate the effect of sports taping on golf swing when wearing functional inner-wear. The subjects of this study were 8 male golfers belonging to Korea Professional Golf Association, and Launch monitor and Trackman were used to find out golf club action, ball pitch, distance, etc. There are three types of clubs: driver, wood, and iron, and the first experiment was carried out using only functional inner-wear. In the second experiment, we experimented with functional inner-wear after sports taping, and we compared and analyzed the distance depending on each experiment, the speed of the ball and the club, and the accuracy of the club face. The results of the study were as follows. As a result of driving distance, according to the presence of sports taping on functional inner-wear, there was a statistically significant difference in the driving swing and wood swing, for club and ball speed, there was a statistically significant difference only in the driving swing. Regarding the accuracy by the presence of sports taping on inner-wear, there was a statistically significant difference in the driving swing, wood swing, and iron swing. In conclusion, the sports taping in the functional inner-wear had a positive effect on golf performance improvement, and we hope that golf inner-wear these two specifications combing will be developed in the future.
\end{abstract}

Keywords: golf swing(골프 스융), functional wear(기능성 웨어), driving distance(비거리), ball and club speed(볼, 클럽 스피드), club face accuracy(클럽 정확도)

\section{Introduction}

과거의 골프는 부유한 특권층이나 선수들만이 수행하는 종목으로 인식되었으나, 
최근에는 실내골프장과 대중골프장의 확산으로 대중 적 스포츠로 자리하고 있다(Park \& Chun, 2000). 골 프에 참여하는 인구가 확산되며, 골프용품산업의 발 전도 함께 활발히 진행되고 있다. 특히 골프웨어는 다양한 기능성과 디자인으로 많은 사람들이 착용하 고 있다. 골프웨어는 기본적으로 화려한 색상을 가지 고 있으며, 골프경기에 적합한 기능성을 보유한다.

골프웨어의 기능성을 살펴보면 첫째, 신체보호 역 할이다. 골프경기는 4시간 이상 야외에서 플레이하기 때문에 쉽게 자외선에 노출된다. 이때 골프웨어는 자 외선을 차단하여 신체를 보호하는 역할을 한다. 또한 골프장은 잔디를 비롯한 식물로 구성되어 골퍼는 벌 레와 식물의 독성에 노출될 수 있다. 골프웨어의 방 수기능은 우천 시 플레이를 돕는 동시에 이와 같은 자연방해물로부터 신체를 보호하는 역할을 한다. 둘 째, 신체 컨디션 유지 및 보강기능이다. 전언한 바와 같이 눈과 비로부터 신체를 보호하며, 땀을 배출할 수 있는 방수기능을 동반해야 한다. 또한 체온유지를 위해 땀을 빠르게 흡수하는 동시에 빠르게 말려주는 흡수기능과 속건기능을 가지고 있다. 이를 보조하는 골프웨어의 기능으로 통풍기능, 발열기능도 요구된다. 셋째, 골프스윙은 매번 같은 방식의 움직임이 반복되 며, 골퍼들은 주머니에 골프공과 골프티 등을 보관함 으로 적절한 내구성과 수납기능이 포함되어야 한다. 넷째, 마지막으로 골프스윙은 단순해 보이지만, 각 운 동단계에 따른 정확한 자세와 힘을 요구하고 있다. 따라서 골프스윙 움직임에 적합한 신체보강 기능성 이 필요하다.

그러나 골프를 즐기는 모든 이들이 이와 같이 골프 수행을 위한 기능성 훈련에 참여하기에는 비용, 장소, 시간 등에 대한 제약을 받기 때문에 어려움을 가지고 있다. 따라서 이와 같은 신체기능을 보완하여 골프수 행능력의 향상을 도모할 수 있는 새로운 방법으로 기 능성 이너웨어가 제시되고 있다.

기능성 이너웨어는 일반적인 골프웨어 내부에 착 용하며, 특정 부위에만 착용하는 부분형 기능성 이너 웨어도 발견된다. 기능성 이너웨어는 근육에 일정한 압박을 가함으로써 근육피로를 줄이며, 효율적인 근 육계의 움직임을 유도함으로 효과적인 운동수행을 유 도한다(Kraemer et al., 2010; McLaren, Helmet, Home, \& Blanchonette, 2010). 이와 더불어 국내 선행연구
(Kim \& Kim, 2015)에서도 기능성 이너웨어가 운동학 적 변인에 긍정적인 연구결과가 나타났지만, 이것이 실제 스윙에 얼마나 긍정적인 영향을 미칠지 알아볼 필 요가 있다. 더불어 골프스윙에서 사용되는 근골격계 에 직접적인 영향을 미칠 수 있는 기능성 이너웨어의 개발을 위한 학문적 지식과 근거개발이 필요하며, 이 와 같은 상품개발을 위한 연구가 절실한 상황이다.

이와 같은 배경으로 인해 본 연구는 스포츠 기능성 이너웨어가 골프스윙 결과에 미치는 영향을 확인하 는 동시에 보다 골프 종목에 특화된 기능성 이너웨어 개발을 위해 스포츠테이핑 기법을 활용하여 그 효과 를 검증하고자 한다. 위와 같은 목적을 달성하기 위 하여 기능성 이너웨어와 스포츠테이핑을 접목한 상 태에서 나타나는 골프클럽 스피드, 볼 스피드, 비거 리, 스윙정확성 등의 차이를 비교하여 기능성 이너웨 어와 스포츠테이핑 접목의 효과성을 검증하는데 주 된 목적을 둔다.

본 연구의 결과를 통해 골프스윙에 적합한 기능성 이너웨어를 개발하는데 중요한 근거자료로 이용되길 기대한다.

\section{Background}

\section{Functional wear}

의류학에서 기능주의는 과학을 기반으로 새로운 소 재와 형태의 발전에서 시작되었으며, 90 년대 기술의 발달과 생활수준의 향상으로 인간의 편리성과 활동성 을 중심으로 기능성 제품들이 등장하기 시작하였다. 이러한 기능성 의류는 다시 건강 지향성 의류와 기 능 지향성 의류로 나누어 설명할 수 있다. 건강 지향 성 의류란 의류를 통해 사람이 건강을 유지하고 발전 시킬 수 있는 방법을 모색하는 과정이라고 이야기할 수 있는데, 그 예로 천연 섬유, 유기농 섬유, 인체에 무해한 섬유 등을 예로 들 수 있다(Choi, 2007). 반면, 기능 지향성 의류는 인간의 편리와 안전을 최우선으 로 생각하여 신체활동의 효율성을 중시한 기능성 의 복이라고 할 수 있다. 다시 말해 신소재를 사용하여 신체적, 상황적 어려움에 처한 인간 활동에 도움을 주며, 실용성과 합리성, 효율성을 바탕으로 형성하는 의류를 의미한다(Fuad-Luke, 2002).

또, 기능 지향성 의류를 첨단 과학기술의 활용을 
바탕으로 한 스마트 웨어(smart wear)와 과학기술을 통해 개발된 친환경적 기능성 소재의 의류, 마지막으 로 하나의 복식이 다양한 기능을 갖춰 편리를 도모하 는 트랜스포머블(trasformable) 의류로 구분할 수 있 다(Park, 2011). 본 연구에서 사용되는 기능성 이너웨 어는 과학기술을 통해 개발된 친환경적 기능성 소재 의 의류라고 볼 수 있는데 이러한 기능성 소재는 UV 차단, 스트레치, 흡습 속건, 향균 방취, 콜라겐 가공, 정전기 방지, 온도 조절 등의 기능을 가지고 있다.

스포츠용 기능성 이너웨어는 운동하는 사람들이 자 신이 속한 상황에서 쾌적하고 오랜 시간 스포츠를 즐 길 수 있도록 흡한 속건 기능이 있고, 부드러운 촉감 의 소재를 주로 사용한다. 또, 피부를 쾌적하게 유지 하고, 피부의 쾌적성에 중점을 두고 개발하는데, 이 중에서도 방수, 방습성, 투습성 및 통기성 등 피복 재 료의 수분과 열의 이동성질을 중요하게 작용을 한다 (Lee, 2009).

\section{Sports taping}

스포츠 테이핑(sport taping)은 인체의 근육과 유사 한 신축성을 가진 테이프를 악화된 근육 부위에 붙여 근막, 인대, 근육 등의 통증을 완화시킴과 동시에, 부 상 위험부위에 부착하여 빠른 회복과 부상방지를 하 는 치료방법이다(Kang, Kim, \& Lee, 2010). 과거의 테이핑은 피부 바로 아래쪽의 근육이나 내부의 기관 에 자극을 주어 관절의 보강 또는 보호, 부종의 감소, 급성 손상 시 관리를 위해 사용해 왔으나(Leanderson, Ekstam, \& Salomonsson, 1996), 최근에는 선수들의 근력, 근 파워, 근지구력 등의 기능 향상에 도움이 되 는 것으로 알려져 경기력 향상을 위해 많이 사용되고 있다(Host, 1995).

테이핑은 탄력의 여부와 처치 방법에 따라 스파이 랄테이핑요법(비탄력테이핑요법)과 키네시오테이핑 요법(탄력테이핑요법), 정형외학적테이핑요법(비탄력 과 탄력을 혼합하여 사용하는 밸런스테이핑요법) 등 으로 나눌 수 있고, 최근에는 아로마요법이나 발포 기능 등을 첨부한 기능성 테이핑요법도 사용되어지 고 있다(Yang, 2008). 흔히 테이핑을 이야기하면 키 네시오(탄력)테이핑을 의미하는데, 키네시오테이핑은 근육이 지나치게 늘어나지 않고, 근방추와 건기관 반 사에 의한 기전으로 근수축이 일어나 근육을 좀 더
용이하게 움직일 수 있게 도와주며, 통증 수용기에 대한 자극을 감소시켜 통증이 완화되고, 몸속의 순환 을 개선하여 자연 치유력을 용이하게 만들어낸다(Kim, 2006). 본 연구에서 또한 키네시오테이핑요법을 이용 하여 실험실 진행하였다.

\section{Golf swing}

골프스윙의 각 단계에서 요구되는 신체적 특성을 알아보면, 골프스윙의 첫 단계인 어드레스에서 중시 되는 특성은 양발의 신체균형, 일직선으로 펴진 척추 의 각도, 이완된 팔 근력이 강조된다. 백스윙에서는 어드레스의 척추각도를 유지할 수 있는 척추기립근의 역할, 유연한 어깨관절의 회전이 요구되며, 백스윙 탑 에서는 적절한 등근육의 긴장도와 어깨관절의 유연 성이 필요하다. 다운스윙이 시작되기 직전의 전환동 작에서는 고관절의 자연스러운 회전과 이어지는 상 체의 일련의 순서를 가진 움직임이 중요하다. 임팩트 동작에서는 다시 척추기립근과 둔근의 적절한 사용 이 필요하며, 부드러운 팔동작이 이어져야 한다. 이러 한 동작들은 척추 주변근, 어깨, 팔의 근골격계의 조 화로운 움직임으로 협응을 이뤄 적절한 타이밍을 만 들어낼 때 효과적인 수행이 나타난다(Moon, 2004).

최근 골프기능성 훈련에 대한 연구가 이어지며, 골 프에 적합한 근골격계의 능력에 대한 관심이 높아지 고 있는 실정이다. 골프에서 사용되는 주된 상체근육 은 팔꿈치근(anconeus), 삼각근(deltoid), 극상근(supraspinous), 극하근(infraspinous), 승모근(trapezius), 척주 기립근(spinal erector)으로 알려져 있다(Kang, 2009). 이와 같은 근육들이 골프스윙에서 근육의 길이가 늘 어나는 원심성 수축과 이어지는 구심성 수축이 힘을 만들어낼 때 가장 효과적인 수행이 나타날 수 있다 (Park, Oh, Baik, \& Kim, 1997).

\section{Methods}

\section{Subject}

본 연구에 사용된 기능성 이너웨어는 현재 국내에 서 시판되는 스포츠 전문브랜드 $\mathrm{N}$ 사의 $\mathrm{P}$ 제품을 선택 하였으며, 골프 스윙동작을 수행하는데 있어 사용되 는 근육들의 움직임에 불편함이 없는 스판덱스(span$\mathrm{dex}$ ) 원단소재를 사용하였다. 등 부위에는 메쉬(mesh) 

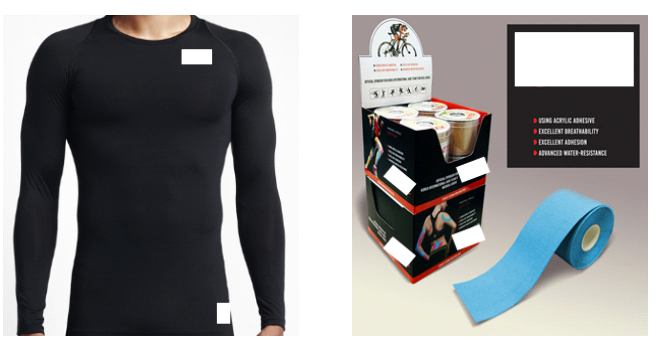

<Fig. 1> Functional inner-wear and sports taping From. Nike. (n.d.). http://www.nike.co.kr; M Korea. (n.d.). http://dhmedicare.com

$<$ Table 1> Characteristics of subject

\begin{tabular}{c|c|c|c|c}
\hline $\begin{array}{c}\text { Subject } \\
(\text { person})\end{array}$ & $\begin{array}{c}\text { Age } \\
(\mathrm{yrs})\end{array}$ & $\begin{array}{c}\text { Height } \\
(\mathrm{cm})\end{array}$ & $\begin{array}{c}\text { Weight } \\
(\mathrm{kg})\end{array}$ & $\begin{array}{c}\text { Career } \\
(\mathrm{yrs})\end{array}$ \\
\hline 8 & $29.1 \pm 3.27$ & $175.64 \pm 7.57$ & $73.14 \pm 6.23$ & $11.63 \pm 2.50$ \\
\hline
\end{tabular}

패널을 사용하여 땀 배출에 대한 통기성 기능을 강화 하였으며, 섬유는 폴리에스터( $92 \%)$, 스판덱스 $(8 \%)$ 로 혼용되어 있다. 또, 연구에 사용된 스포츠 테이프(Kinesiology Tape)는 M사의 $\mathrm{M}$ 제품을 사용하였으며, 스 포츠 테이프는 cotton doth, elastic span tex, acrylic $\mathrm{psa}$ 성분으로 구성되어 있다. 본 연구에서 사용한 N 사의 기능성 이너웨이는 스포츠 테이핑의 효과를 극 대화하기위해 시중에 나와 있는 다양한 기능성 이너 웨어 중 절개부분이 적고, 스윙 동작을 하는데 불편 함을 느끼지 않는 정도의 압박을 가진 제품으로 선택 하였다(Fig. 1).

연구에 참여한 대상자들은 한국프로골프협회(KPGA) 에 소속되어 있는 남자 골퍼 8 명으로 한정하였으며, 모두 오른손을 사용하는 대상자들이다. 실험을 시작 하기에 앞서 참가자들에게 실험에 관한 정보와 절차 등에 대해 충분히 설명을 한 후 자발적인 참여에 의 해 진행되었으며, 참가가 모두에게 연구동의서를 받 았다. 또한, 연구 수행 중 부상이나 개인적인 사유가 발생하였을 시 자유롭게 실험에 참가하지 않아도 되 는 점을 공지하였으며, 대상자들의 특성은 〈Table 1〉 과 같다.

\section{Equipment}

골프 스윙 동작 수행 시 기능성 이너웨어만 착용 하였을 때와 스포츠 테이핑을 부착한 다음 기능성 이
너웨어를 착용하였을 때의 수행결과 차이(골프클럽의 움직임, 볼의 구질, 비거리 등)를 알아보기 위해 골프 타구 분석기(Launch monitor) 트랙맨(Trackman)을 이 용하였으며, 신장체중계를 이용하여 참가들의 신장과 체중을 측정하였다.

골프 스윙 동작 수행 시 스포츠 테이핑과 각 근육의 관련성에 대한 선행연구(Kang, 2009; Kang, Moon, \& Chio, 2006)와 스포츠 테이핑 전문가 1인(장애인국가 대표 의무트레이너)의 자문을 통해 테이핑을 실시하 였으며, 팔꿈치근(anconeus), 삼각근(deltoid), 극상근 (supraspinous), 극하근(infraspinous), 승모근(trapezius), 척주기립근(spinal erector) 총 6부위에 테이핑을 실시 하였다.

본 연구에 사용된 구체적인 실험장비(Table 2)와 대상자의 스포츠 테이핑 부착위치(Fig. 2)는 다음과 같다.

\section{Experimental procedure}

본 실험은 $\mathrm{Y}$ 대학의 실내 실험실에서 실시하였으며, 골프 스윙 동작을 수행하는데 충분한 공간을 확보하 였다. 타구가 진행하는 앞부분에는 스크린을 설치하

<Table 2> Measurement and instrument

\begin{tabular}{c|c|c}
\hline Tool & Model & Manufacturer \\
\hline $\begin{array}{c}\text { Weighing } \\
\text { machine }\end{array}$ & SH-M108 & $\begin{array}{c}\text { Samhwa } \\
\text { (Korea) }\end{array}$ \\
\hline Golf analyzer & Trackman pro & $\begin{array}{c}\text { Trackman } \\
\text { (Denmark) }\end{array}$ \\
\hline
\end{tabular}
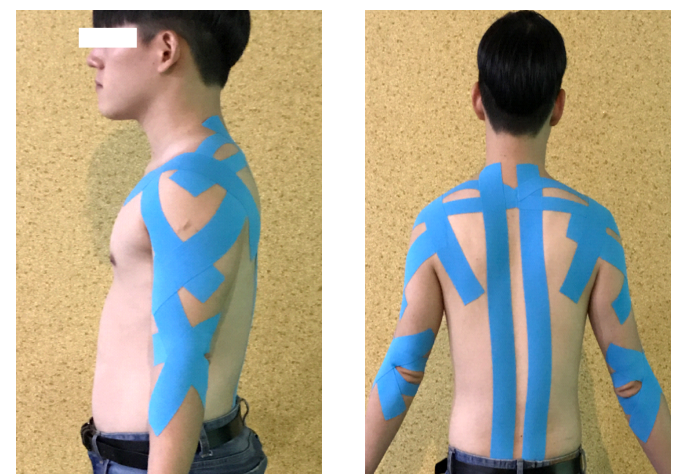

<Fig. 2> Location with sports taping Photographed by the author. (April 11, 2017) 
였고, 옆 부분에는 그물망을 설치하여 실험의 안정성 을 확보하였다.

실험대상자들에게 실험실 및 실험장비, 실험방법 에 대한 충분한 설명을 실시한 후, 정확한 스윙을 측 정하기 위해 실험에 들어가기 전 10 분간 연습스윙을 실시하였다. 또한 실험대상자들에게 실험을 실시하기 전 48시간 동안은 무리한 운동이나 물건을 들지 않을 것을 권고하여 최상의 컨디션을 유지하도록 지시하 였다.

제 1 실험은 모든 피험자가 연구에서 사용한 기능 성 이너웨어만을 착용하고, 그 위에 정식 골프복장을 착용한 후 드라이버, 우드, 아이언 순으로 각 10 번씩 스윙 동작을 수행하였으며, 연속된 스윙 동작으로 인 한 피로누적을 감안하여 조건 사이에 약 5 분 이상의 충분한 휴식을 취하도록 하였다.

제 2실험은 제 1실험이 끝난 1주일 후에 동일한 장 소와 동일한 인원을 대상으로 먼저 스포츠 테이핑을 실시한 후 그 위에 기능성 이너웨어와 골프복장을 착 용하게 하였다. 나머지 실험절차는 1 차와 동일하게 실시하였다.

\section{Data analysis}

본 연구에서 기능성 이너웨어만 착용하고 골프 스 윙 동작을 수행했을 때와 이와 더불어 스포츠 테이핑 을 실시한 후 기능성 이너웨어를 착용하고 골프 스윙 동작 수행의 결과를 분석하기 위해 골프 타구 분석기 를 사용하여 드라이버, 3 번 우드, 7 번 아이언의 비거 리(Carry [CA]), 스피드(Club Speed [CS]), (Ball Speed [BS]), 볼을 맞는 임펙트 순간의 정확도(Face Angle $[\mathrm{FA}])$ 를 측정하였다.

비거리 측정은 $\operatorname{Carry}(\mathrm{CA})$ 변인을 사용하였는데, $\mathrm{CA}$ 는 볼이 날아가서 떨어진 곳까지의 거리를 의미한 다. 스피드 측정은 Club Speed(CS)와 Ball Speed(BS) 변인을 사용하였는데, $\mathrm{CS}$ 는 스윙 중 클럽 헤드가 볼 을 치고 나갈 때의 헤드 속도, 즉 임팩트 순간의 속도 를 측정한 것을 의미하며, $\mathrm{BS}$ 는 헤드에 맞아 날아가 는 볼의 초속을 의미한다. 마지막으로 스윙의 정확도 측정은 Face Angle(FA) 변인을 사용하여 측정하였는 데, $\mathrm{FA}$ 는 임팩트 시 클럽페이스가 열리고 닫힌 정도 를 의미하며, 페이스가 오픈되면 + 로, 클로스 되면 로 나타난다.

\section{Statistical analysis}

골프 스윙 동작 수행 시 기능성 이너웨어만 착용 하였을 때와 스포츠 테이핑을 부착한 다음 기능성 이 너웨어를 착용하였을 때의 수행결과 차이(골프 스윙 의 헤드스피드, 볼 스피드, 비거리, 정확성 등)를 알아 보기 드라이버, 우드, 아이언을 각각 10 번의 스윙을 실시하였다. 각각의 10 번의 수행 중 자신이 최대값과 최소값을 제외한 나머지 8 회의 평균화한 값을 분석 자료로 활용하였다.

8 명의 연구대상자별 스윙 동작 수행 시 분석에 적 합한 각각 8 번의 데이터[ 8 명 * 2가지 조건(이너웨어 착용 시 스포츠 테이핑 부착 유-무) * 3 개 동작(드라 이버 스윙, 우드 스윙, 아이언 스윙) * 4개의 변인(Carry, Club Speed, Ball Speed, Face Angle Accuracy)]를 수 집하였다. 모든 변인은 Microsoft office excel 2013을 이용하여 평균 $(M)$ 과 표준편차 $(S D)$ 를 산출하였으며, 스포츠 테이핑의 부착 유무에 따른 수행결과의 차이 를 확인하기 위해 통계프로그램인 SPSS 23.0을 이용 하여 대응표본 $t$ 검증(Paired $t$-test)을 실시하였으며, 이때 통계적 유의수준은 .05로 설정하였다.

\section{N. Results and Discussion}

본 연구에 참여한 대상자들은 기능성 이너웨어 안 에 스포츠 테이핑 부착 유-무에 따라 골프 스윙 동 작 수행을 실시하였고, 그에 따른 운동학적 변인(비 거리, 스피드, 정확성)들의 분석결과는 다음과 같다.

\section{Distance}

기능성 이너웨어 안에 스포츠 테이핑 부착 유·무에 따른 드라이버, 우드, 아이언 스윙 동작 수행 시 캐리 (Carry)의 차이 검증은 〈Table 3〉과 같이 나타났다.

각 클럽별 기능성 이너웨어 안에 스포츠 테이핑 부 착 유-무에 따른 캐리(Carry) 결과를 살펴보면, 드라 이버 스윙에서는 기능성 이너웨어 안에 스포츠 테이 핑을 부착하였을 때가 부착하지 않았을 때보다 평균

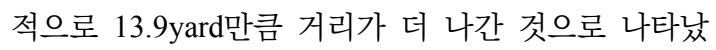
다 $(p<.05)$. 또한 우드 스윙 결과에서도 드라이버 스윙 결과와 마찬가지로 스포츠 테이핑을 부착하였을 때 $17.0 \mathrm{yard}$ 만큼 거리다 더 나간 것으로 나타났고 $(p<.05)$, 아이언 스윙결과에서도 역시 테이핑을 부착하였을 
때 0.88yard 더 멀리 날아갔다. 〈Fig. 3〉은 각 클럽의 캐리(Carry) 결과를 그래프로 나타낸 것이다.

비거리의 차이를 확인할 수 있는 캐리(CA)는 스포 츠 테이핑을 접목한 기능성 이너웨어 착용에서 보다 효과가 크다고 이야기할 수 있을 것이다. 특히 그 차 이는 드라이버 샷과 우드 샷에서 유의한 효과를 나타 내었다.

이러한 비거리 측정의 결과는 각 클럽의 스윙동작 을 실시할 때, 하지의 움직임을 최소한으로 하고, 상 지의 허리 및 어깨의 회전을 크게 하는 것이 중요하 다. $\operatorname{Kim}$ and $\operatorname{Kim}(2015)$ 의 연구를 통해 드라이버 스 윙 시 기능성 이너웨어를 착용하였을 때가 착용하지 않았을 때 보다 신체의 움직임을 최소화하는데 긍정 적인 영향을 미치고, 신체중심의 분산이동이 줄어들 어 스윙의 일반성과 강한 임팩트를 만들어 낸다고 보 고하고 있다. 또, 스포츠 테이핑은 피부와 근육의 탄 성이 유사한 천을 신체에 부착하여 특정 부위의 근육 과 관절의 기능을 향상시켜 주는 방법으로서 많이 사

$<$ Table 3> Result of Carry

(Unit: yard)

\begin{tabular}{|c|c|c|c|c|}
\hline Event & Group & $n$ & Mean $\pm S D$ & $t$ \\
\hline \multirow{2}{*}{ Driver } & Non-taping & \multirow{2}{*}{8} & $225.51 \pm 18.86$ & \multirow{2}{*}{$-2.987^{*}$} \\
\hline & Taping & & $239.36 \pm 24.94$ & \\
\hline \multirow{2}{*}{ Wood } & Non-taping & \multirow{2}{*}{8} & $201.81 \pm 23.31$ & \multirow{2}{*}{$-3.303^{*}$} \\
\hline & Taping & & $218.81 \pm 27.31$ & \\
\hline \multirow{2}{*}{ Iron } & Non-taping & \multirow{2}{*}{8} & $157.58 \pm 13.02$ & \multirow{2}{*}{-.225} \\
\hline & Taping & & $158.46 \pm 16.86$ & \\
\hline
\end{tabular}

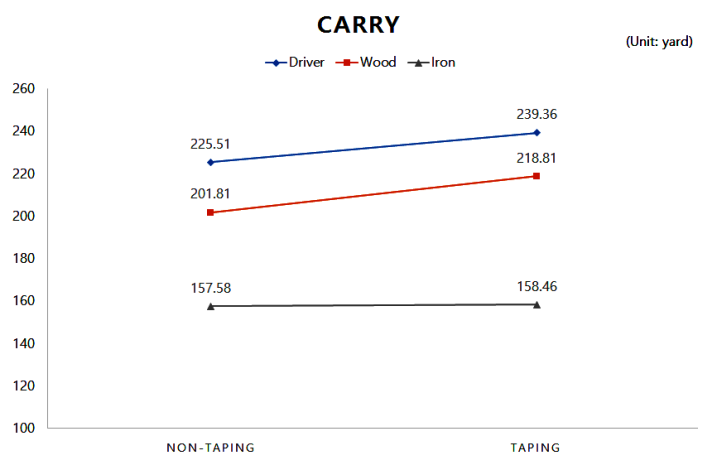

<Fig. 3> Result of Carry
용되고 있다(Lee, Kim, \& Lee, 2002). 골프의 비거리 는 지상의 중심근육을 통해 기능적인 사슬운동을 수 행하는데 필요한 근원적인 힘을 발생시키는데(Park \& Ahn, 2016), 스포츠 테이핑과 기능성 이너웨어가 이 기능적 운동을 효과적으로 할 수 있게 매개체 역 할을 수행한다고 이야기할 수 있다.

\section{Speed}

기능성 이너웨어 안에 스포츠 테이핑 부착 유-무 에 따른 드라이버, 우드, 아이언 스윙 동작 수행 시 클럽 스피드(Club Speed)와 볼 스피드(Ball Speed)의 차이 검증은 〈Table 4〉, 〈Table 5〉와 같이 나타났다.

먼저 드라이버 클럽의 헤드 스피드(CS) 결과를 살 펴보면, 기능성 이너웨어 안에 테이핑을 하였을 때가 그렇지 않았을 때보다 $6.80 \mathrm{mph}$ 더 빠른 것으로 나타 났으며( $p<.05)$, 우드 클럽(5.45mph)과 아이언 클럽(2.95 $\mathrm{mph}$ )에서도 테이핑을 실시하였을 때가 더 높게 나타 났지만 통계적으로 유의한 차이는 보이지 않았다. 〈Fig. 4〉는 클럽의 헤드 스피드의 결과를 그래프로 나 타낸 것이다.

볼 스피드(BS)의 결과를 살펴보면, 클럽 헤드 스피 드와 마찬가지로 기능성 이너웨어 안에 테이핑을 실 시하였을 때가 그렇지 않았을 때보다 높은 결과가 나 타났다. 특히 드라이브 스윙을 통해 전달된 볼의 스피 드 결과를 살펴보면 테이핑을 했을 때가 $6.72 \mathrm{mph}$ 더 빠른 것으로 나타났으며( $p<.05)$, 우드 스윙 $(5.68 \mathrm{mph})$ 과 아이언 스윙 $(1.15 \mathrm{mph})$ 을 통한 볼 스피드 결과에서 테이핑을 하였을 때가 더 높게 나타났지만, 통계적으 로 유의한 차이는 보이지 않았다. 〈Fig. 5〉는 각 클럽 을 통한 볼 스피드(BS)의 차이의 결과를 그래프로 나 타낸 것이다.

골프스윙 능력의 차이를 확인하기 위하여 클럽 헤 드 스피드(CS)와 볼 스피드(BS)의 각각 변화를 확인 한 결과, 가장 긴 클럽인 드라이버 샷에서 스포츠테 이핑을 접목한 기능성 이너웨어 착용이 더 빠른 스피 드를 보이며 유의한 차이를 나타냈다. 골프스윙(드라 이버 샷, 우드 샷, 아이언 샷) 중 가장 빠른 스피드를 요구하는 것이 드라이버 샷이다. 다른 골프스윙은 더 멀리 공을 보내기 위한 노력에 앞서 더 정확한 곳에 공을 보내는 목적이 강하다. 반면, 드라이버 샷은 비 교적 넓은 페어웨이에 안착하는 것을 목적으로 하기 
때문에 보다 멀리 보내려는 노력이 강하게 나타날 수 있다. 따라서 골퍼는 드라이버 샷에서 보다 많은 에 너지를 생성시킨다. 이 과정에서 골프 스윙에 관련된 근육의 사용이 증가하게 된다. 반면, 아이언 샷의 결 과는 드라이버나 우드에 비해 상대적으로 스윙 궤적 이 작기 때문에 다른 클럽에 비해 차이가 크지 않은 것으로 사료된다. 따라서 본 연구의 결과에 따라 스 포츠테이핑을 접목한 기능성 이너웨어는 골프스윙에 서 상체의 근육움직임을 보조하여 골프 클럽 스피드 를 향상시켜 비거리가 증가하게 된다는 것을 확인할 수 있다. 이와 같은 결과는 스포츠 테이핑을 바탕으 로 제작된 다기능성 웨어를 착용하였을 때 골프 동작 의 움직임과 클럽의 스피드가 그렇지 않을 때보다 향 상된다는 연구 결과들(Kim, Park, \& Uh, 2014; Lim, 2009)과 골프 스윙에서 스포츠 테이핑 요법을 실시하 였을 때 보다 적은 근활성도로 동일한 동작으로 강한 힘을 발현할 수 있다는 연구(Kang et al. 2006)와 같 은 맥락을 하고 있다.

$<$ Table 4> Result of Club Speed(CS) (Unit: mph)

\begin{tabular}{c|c|c|r|c}
\hline Event & Group & $n$ & Mean $\pm S D$ & $t$ \\
\hline \multirow{2}{*}{ Driver } & Non-taping & & $99.40 \pm 5.61$ & \multirow{2}{*}{8} \\
\cline { 2 - 2 } & Taping & & $106.20 \pm 6.09$ & \\
\hline \multirow{2}{*}{ Wood } & Non-taping & \multirow{2}{*}{8} & $94.55 \pm 6.22$ & \multirow{2}{*}{-2.017} \\
\cline { 2 - 2 } & Taping & & $100.60 \pm 9.19$ & \\
\hline \multirow{2}{*}{ Iron } & Non-taping & \multirow{2}{*}{8} & $83.05 \pm 5.72$ & \multirow{2}{*}{-1.274} \\
\cline { 2 - 2 } & Taping & & $86.00 \pm 4.16$ & \\
\hline
\end{tabular}

${ }^{*} p<.05$

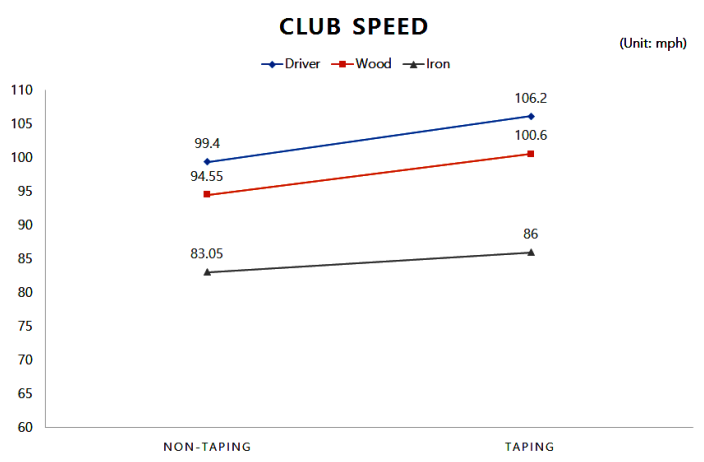

$<$ Fig. 4> Result of Club Speed(CS)
<Table 5> Result of Ball Speed(BS) (Unit: mph)

\begin{tabular}{|c|c|c|c|c|}
\hline Event & Group & $n$ & Mean $\pm S D$ & $t$ \\
\hline \multirow{2}{*}{ Driver } & Non-taping & \multirow{2}{*}{8} & $139.58 \pm 9.36$ & \multirow{2}{*}{$-3.350^{*}$} \\
\hline & Taping & & $146.30 \pm 10.47$ & \\
\hline \multirow{2}{*}{ Wood } & Non-taping & \multirow{2}{*}{8} & $130.25 \pm 10.12$ & \multirow{2}{*}{-1.356} \\
\hline & Taping & & $135.93 \pm 18.86$ & \\
\hline \multirow{2}{*}{ Iron } & Non-taping & \multirow{2}{*}{8} & $110.33 \pm 7.95$ & \multirow{2}{*}{-.615} \\
\hline & Taping & & $111.48 \pm 6.63$ & \\
\hline
\end{tabular}

${ }^{*} p<.05$

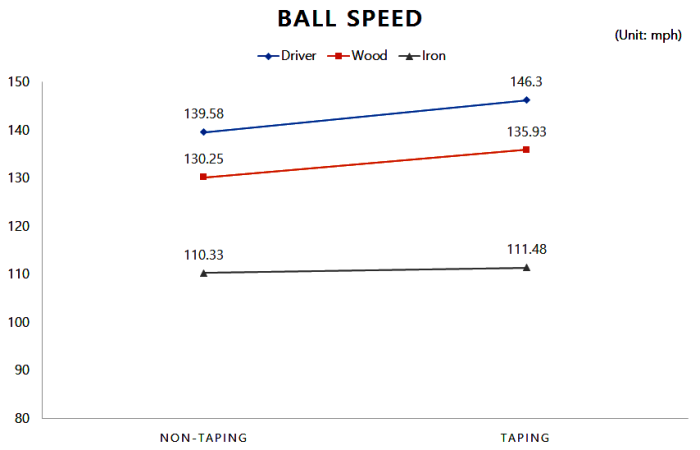

<Fig. 5> Result of Ball Speed(BS)

\section{Accuracy}

각 클럽별 기능성 이너웨어 안에 스포츠 테이핑 부 착 유-무에 따른 드라이버, 우드, 아이언 스윙 동작 수행 시 임팩트 순간 클럽 페이스의 정확도(Face Angle)의 차이 검증은 〈Table 6〉과 같이 나타났다.

기능성 이너웨어 안에 스포츠 테이핑 부착 유- 무 에 따른 클럽 페이스 정확도(FA)의 결과를 살펴보면, 모든 클럽에서 기능성 이너웨어 안에 스포츠 테이핑 을 부착하였을 때가 그렇지 않았을 때보다 높은 결과 가 나타났다.

먼저 드라이버 클럽의 클럽 페이스(FA) 결과를 살 펴보면 테이핑을 하였을 때가 그렇지 않았을 때보다 $-3.27 \mathrm{deg}$ 더 클럽 중심에 맞은 것으로 나타났으며 $(p<$ $.05)$, 우드 클럽결과에서도 $-3.99 \mathrm{deg}$, 아이언 클럽결 과에서도 $-2.8 \mathrm{deg}$ 만큼 테이핑을 실시하였을 때가 더 클럽 중앙에 정확하게 맞는 것으로 나타났다. 〈Fig. 6)은 각 클럽 페이스의 정확도를 사전, 사후 결과를 바탕으로 그래프를 나타낸 것이다. 
골프 스윙의 정확성을 확인하기 위해 알아본 임팩 트 시 클럽페이스의 각도 차이를 분석한 결과, 드라이 버 샷, 우드 샷, 아이언 샷 모두 유의한 차이가 확인 되었다. 골프스윙에서 필요한 능력은 빠른 스피드와 정확한 움직임이다. 운동기술이 완벽하게 이뤄지기 위해서는 적절한 스피드가 나타날 때 정확성이 나타 난다(Schmidt \& Wrisberg, 2008). 본 연구에서 나타 난 정확성의 향상은 선행연구의 결과를 토대로 스포 츠테이핑의 기능으로 확인할 수 있다. 스포츠테이핑 은 근력, 근지구력을 향상시키는 동시에 근육의 기능 을 향상시켜 운동제어와 관련된 운동수행능력을 증 진시킨다(Maitland \& Vadertuin, 2002). 또한 스포츠 테이핑은 근육의 떨림을 잡아주는 역할인 근경련 예 방효과가 있다(Tariq, Haren, Kim, \& Morley, 2005). 이와 같은 기능과 역할로 미루어 볼 때 골프스윙에서 정확성이 향상된 이유를 스포츠테이핑 기능이 적용 된 것으로 생각할 수 있다.

$<$ Table 6> Result of Face Angle Accuracy (Unit: deg)

\begin{tabular}{c|c|c|c|c}
\hline Event & Group & $n$ & Mean $\pm S D$ & $t$ \\
\hline \multirow{2}{*}{ Driver } & Non-taping & \multirow{2}{*}{8} & $5.88 \pm 2.92$ & \multirow{2}{*}{$5.361^{*}$} \\
\cline { 2 - 2 } & Taping & & $2.61 \pm 2.96$ & \\
\hline \multirow{2}{*}{ Wood } & Non-taping & \multirow{2}{*}{8} & $6.29 \pm 2.61$ & \multirow{2}{*}{$7.251^{*}$} \\
\cline { 2 - 2 } & Taping & & $2.30 \pm 3.04$ & \\
\hline \multirow{2}{*}{ Iron } & Non-taping & \multirow{2}{*}{8} & $3.73 \pm 3.78$ & \multirow{2}{*}{$3.886^{*}$} \\
\cline { 2 - 2 } & Taping & & $0.93 \pm 2.15$ & \\
\hline
\end{tabular}

${ }^{*} p<.05$

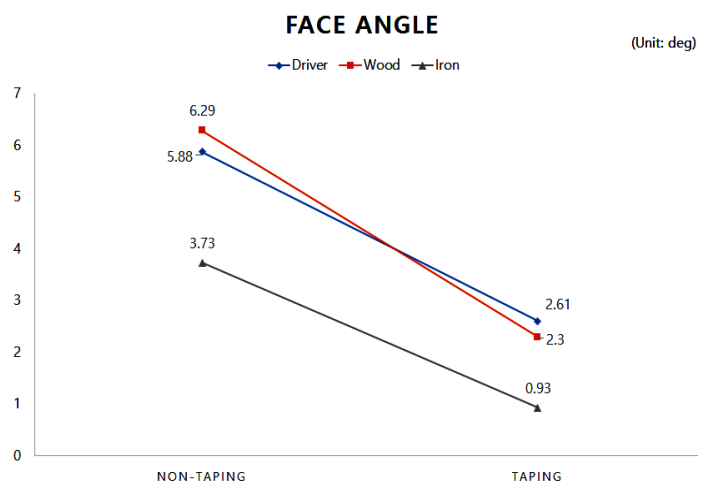

$<$ Fig. 6> Result of Face Angle Accuracy

\section{Conclusion}

기능성 이너웨어 착용 시 스포츠 테이핑 부착에 따 른 골프 스윙에 미치는 효과를 검증하기 위해 본 연 구에서는 한국프로골프협회(KPGA) 소속 골퍼들을 대상으로 기능성 이너웨어 안에 스포츠 테이핑 부착 유-무에 따라 각 클럽의 비거리, 스피드, 정확성을 평가할 수 있는 변인들이 어떠한 형태로 변화하였는 지 비교분석하였다.

본 연구의 결과는 다음과 같다. 첫째, 골프 비거리 실험에서 기능성 이너웨어 안에 골프 스윙에 사용되 는 근육 부위에 스포츠 테이핑을 실시하였을 때, 테이 핑을 하지 않았을 때보다 드라이버 스윙과 우드 스윙 에서 통계적으로 유의한 차이를 나타내었다. 비거리 의 차이를 확인할 수 있는 캐리(CA)는 스포츠 테이핑 을 접목한 기능성 이너웨어 착용에서 보다 효과가 크 다고 이야기할 수 있는데, 이것은 클럽의 스윙 동작 을 실시할 때 상지의 허리와 어깨의 강한 회전으로 실시하는데, 테이핑과 이너웨어가 강한 임팩트를 만 들어 내는데 긍정적인 역할을 하는 것임을 시사하였 다. 둘째, 골프스윙 능력의 차이를 확인하기 위하여 클럽 헤드 스피드(CS)와 볼 스피드(BS)의 각각 변화 를 확인한 결과, 가장 긴 클럽인 드라이버 샷에서 스 포츠테이핑을 접목한 기능성 이너웨어 착용이 더 빠 른 스피드를 보이며 유의한 차이를 나타내었다. 골퍼 는 드라이버 샷에서 보다 많은 에너지를 생성시키며, 이러한 과정에서 근육의 사용이 증가하게 되고, 아이 언 샷의 결과는 드라이버나 우드 샷에 비해 상대적으 로 스윙 궤적이 작기 때문에 다른 클럽에 비해 편치 가 크지 않은 것으로 사료된다. 셋째, 기능성 이너웨 어 안에 스포츠 테이핑을 부착 유-무에 따른 클럽 페이스 정확도의 결과에서는 모든 클럽에서 기능성 이너웨어 안에 스포츠 테이핑을 부탁하였을 때 그렇 지 않았을 때보다 정확한 결과를 나타내었다.

드라이버, 우드, 아이언 클럽 모두에서 테이핑을 하지 않았을 때보다 테이핑을 하였을 때 클럽페이스 의 평균값이 줄어들어 정확하게 맞아 나가는 것으로 확인되었다. 이러한 결과는 기능성 이너웨어와 스포 츠 테이핑이 근육의 떨림과 기능을 향상시켜 운동제 어와 관련된 운동수행능력을 증진시키는 것으로 판 단되어진다. 
본 연구 수행에 있어 나타난 미래연구에 대한 제언 은 다음과 같다. 본 연구에서 살펴본 스포츠테이핑을 접목한 기능성 이너웨어는 일체형으로 제작된 상품이 아니었다. 따라서 차후 연구에서는 실제 착용이 간편 한 형태의 기능성 이너웨어를 제작하여 재검증할 필 요가 있다. 또, 스포츠테이핑은 선수 또는 운동수행자 에 몸에 맞추어 부착되기 때문에 개인차가 나타날 수 있음으로 보다 세분화된 의류의 범위가 요구된다.

\section{References}

Choi, E.-K. (2007). A study on eco fashion design through the application of the formative beauty of Korean traditional dress to Korean paper textile. Unpublished doctoral dissertation, Sungshin Women's University, Seoul, Korea.

Fuad-Luke, A. (2002). The eco-design handbook: A complete sourcebook for the home and office. London: Thames \& Hudson.

Host, H. H. (1995). Scapular taping in the treatment of anterior shoulder impingement. Physical Therapy, 75(9), 803-812. doi:10.1093/ptj/75.9.803

Kang, H.-Y., Moon, G.-S., \& Chio, J.-Y. (2006). Electromyographical analysis of the upper limb according to application of sport-taping on golf swing. The Korean Journal of Physical Education, 45(1), 789-797.

Kang, J. H., Kim, S. H., \& Lee, K. J., (2010). The illustrated guide to taping therapy for musculoskeletal pain. Seoul: Medianbooks.

Kang, S.-B. (2009). The effect of taping therapy on distance and accuracy of golf drive shot. Journal of Golf Studies, 3(1), 91-98.

Kim, J. W., Park, S. K., \& Uh, M. K. (2014). Effects of golf drive swing on multiple functional wear wearing. The Research Journal of the Costume Culture, 22(4), 632-639. doi:10.7741/rjcc.2014.22. 4.632

Kim, J.-W., \& Kim, I. (2015). The effect of wearing functional inner-wear on kinematical variables during a golf drive swing. The Journal of the
Korean Society of Knit Design, 13(1), 10-17.

Kim, K.-W. (2006). The effect of taping treatment on painful motion limitation in lumbar and pelvic region. Unpublished master's thesis, Pusan National University, Busan. Korea.

Kraemer, W. J., Flanagan, S. D., Comstock, B. A., Fragala, M. S., Earp, J. E., Dunn-Lewis, C., ... \& Maresh, C. M. (2010). Effects of a whole body compression garment on markers of recovery after a heavy resistance workout in men and women. The Journal of Strength \& Conditioning Research, 24(3), 804-814. doi:10.1519/JSC.0b013e3 $181 \mathrm{~d} 33025$

Leanderson, J., Ekstam, S., \& Salomonsson, C. h. (1996). Taping of the ankle-the effect on postural sway during perturbation, before and after a training session. Knee Surgery, Sports Traumatology, Arthroscopy, 4(1), 53-56. doi:10.1007/BF0 1565999

Lee, H.-S., Kim, J.-J., \& Lee, J.-M. (2002). Effect on performances of taping manifestation of muscle power after isokinetic sustaining-exercise. The Korea Journal of Sports Science, 11(2), 777-787.

Lee, Y. S. (2009). A study on the development of the protective inner-pants for snow boarders. Unpublished master's thesis, Ewha Womans University, Seoul, Korea.

Lim, Y.-T. (2009). The analysis of swing plane of elite golfers during drive swing. Korean Journal of Sports Biomechanics, 19(1), 59-66. doi:10. 5103/KJSB.2009.19.1.059

M Korea. (n.d.). M-TEX. Retrieved April 29, 2017, from http://dhmedicare.com/product/detail_gallery. html?product_no $=26 \&$ cate_no $=51 \&$ display_group $=1$

Maitland, M. E., \& Vandertuin, J. F. (2002). The effect of compression clothing on muscular strength and endurance. Medicine \& Science in Sports \& Exercise, 34(5), S173.

McLaren, J., Helmer, R. J. N., Horne, S. L., \& Blanchonette, I. (2010). Preliminary development of a 
wearable device for dynamic pressure measurement in garments. Procedia Engineering, 2(2), 3041-3046. doi:10.1016/j.proeng.2010.04.108

Moon, B.-I. (2004). The analysis of kinematic and kinetic characteristics during the golf swing. Unpublished doctoral dissertation, Chosun University, Gwangju. Korea.

Nike. (n.d.). Nike Pro. Retrieved April 29, 2017, from http://www.nike.co.kr/goods/showGoodsDetail. lecs?goods No=NK31055634\&colorOptionValueC ode $=703089-010$

Park, C.-H., Oh, S.-K., Baik, S.-K., \& Kim, C.-W. (1997). The comparision of EMG between skilled and unskilled golf player in swing. Journal of Sports Science Research, 15, 195-204.

Park, H. K. (2011). A study on the development of eco fashion design through analysis of Korean fashion brands. Unpublished master's thesis, ChungAng University, Seoul. Korea.

Park, J.-G., \& Chun, S.-H. (2000). A study on the satisfaction degrees of the national park facilities.
Journal of Sport and Leisure Studies, 13, 465484.

Park, S.-H., \& Ahn, B.-O. (2016). Analysis of core muscles activity of distance and fairway hit during down swing of golf driver shot. Journal of the Korea Entertainment Industry Association, 10(6), 227-233. doi:.21184/jkeia.2016.12.10.6.227

Schmidt, R. A., \& Wrisberg, C. A. (2008). Motor learning and performance: A situation-based learning approach (4th ed). Champaign, IL: Human Kinetics.

Tariq, S. H., Haren, M. T., Kim, M. J., \& Morley, J. E. (2005). Andropause: Is the emperor wearing any clothes?. Reviews in Endocrine \& Metabolic Disorders, 6(2), 77-84. doi:10.1007/s11154-0056719-4

Yang, K.-H. (2008). The effects of taping therapy on parameter of pain substances of blood and muscle activites. Unpublished doctoral dissertation, Daegu Haany University, Gyeongsangbukdo, Korea. 